\title{
Leaching behaviour and ecotoxicity evaluation of chars from the pyrolysis of forestry biomass and polymeric materials
}

\author{
M. Bernardo ${ }^{a, *}$, S. Mendes ${ }^{a}$, N. Lapa ${ }^{a, b}$, M. Gonçalves ${ }^{a}$, B. Mendes ${ }^{a}$, F. Pinto ${ }^{b}$, H. Lopes ${ }^{b}$ \\ ${ }^{a}$ Unidade de Biotecnologia Ambiental, Faculdade de Ciências e Tecnologia, Universidade Nova de Lisboa, 2829-516 Caparica, Portugal \\ ${ }^{\mathrm{b}}$ Unidade de Tecnologias de Conversão e Armazenamento de Energia, Laboratório Nacional de Energia e Geologia, Ed. J, Estrada do Paço do Lumiar 22, 1649- \\ 038 Lisboa, Portugal
}

\section{A R T I C L E I N F O}

\section{Article history:}

Received 6 December 2013

Received in revised form

9 May 2014

Accepted 12 May 2014

Available online 3 June 2014

Keywords:

Pyrolysis

Chars

Leaching

Ecotoxicity

Environmental risk

\begin{abstract}
A B S T R A C T
The main objective of this study was to assess the environmental risk of chars derived from the pyrolysis of mixtures of pine, plastics, and scrap tires, by studying their leaching potential and ecotoxicity. Relationships between chemical composition and ecotoxicity were established to identify contaminants responsible for toxicity. Since metallic contaminants were the focus of the present study, an EDTA washing step was applied to the chars to selectively remove metals that can be responsible for the observed toxicity. The results indicated that the introduction of biomass to the pyrolysis feedstock enhanced the acidity of chars and promote the mobilisation of inorganic compounds. Chars resulting from the pyrolysis of blends of pine and plastics did not produce ecotoxic eluates. A relationship between zinc concentrations in eluates and their ecotoxicity was found for chars obtained from mixtures with tires. A significant reduction in ecotoxicity was found when the chars were treated with EDTA, which was due to a significant reduction in zinc in chars after EDTA washing.
\end{abstract}

(c) 2014 Elsevier Inc. All rights reserved.

\section{Introduction}

The European Waste Framework Directive (EU, 2008) established the waste management hierarchy that should be respected and applied in the member states of the European community. Recycling and other hierarchical recovery activities such as the energy recovery from wastes are considered key parts of this classification. According to this directive, the thermochemical treatment of wastes without air supply, commonly known as pyrolysis, can be considered a recycling operation since waste materials are reprocessed into three types of products: chars, gases, and heavy compounds that condense as oils when cooled down (tars). The gaseous and liquid fractions can be used as a basic chemical feedstock in the petrochemical and refining industries (Vamvuka, 2011; Al-Salem et al., 2010; Quek and Balasubramanian, 2013). The char can be processed further to be used as adsorbent (González et al., 2009; Méndez-Liñán et al., 2010; Hale et al., 2013), for catalytic applications (Kastner et al., 2009; Zhang et al., 2011), for soil amendment (Uchimiya et al., 2010; Manyá, 2012), and as a metallurgical reducing agent (Griessacher et al., 2012; Kantarelis et al., 2010) among other uses. Alternatively, pyrolysis can also be considered an energy recovery operation, as the three products

\footnotetext{
*Corresponding author. Fax: +351212948543.

E-mail address: mmb11704@fct.unl.pt (M. Bernardo).
}

obtained can be used as fuels because of their calorific content (Vamvuka, 2011; Al-Salem et al., 2010).

The recycling attribute of pyrolysis is one step beyond incineration in the waste hierarchy and for this reason it should be preferred as a thermal treatment. In recent years, pyrolysis have received a great deal of attention from the scientific community and started to be commercially applied (Vamvuka, 2011; Al-Salem et al., 2010; Bosmans et al., 2013) because it can provide the same advantages of incineration (waste reduction by volume and weight) with additional advantages such as reduced gas emissions in volume and toxicity (Zaman, 2010). Therefore, it is expected that waste treatment by pyrolysis will grow in importance in the near future, being anticipated that large amounts of pyrolytic chars will be available as by-products or as main products. It is then important to study the properties, composition, and risk assessment of chars, in order to avoid risks to environmental compartments and to exploit the potential value of these pyrolysis products. In particular, applications of these materials involving contact with or potential exposition to water, require the knowledge of their leaching behaviour and ecotoxicological properties.

Chars are essentially carbon materials that retain the mineral matter initially present in the wastes and may contain significant amounts of pyrolytic tars. Therefore, the release of toxic compounds from chars is a possibility that might restrict their applications, which demands the evaluation of contaminant mobility through leaching tests.

Combining chemical analyses with ecotoxicological tests as an integrated strategy to characterise a given sample has the 